\title{
Preserving Human Rights Media for Justice, Accountability, and Historical Clarification
}

\author{
Jay D. Aronson \\ Carnegie Mellon University
}

Follow this and additional works at: https://digitalcommons.usf.edu/gsp

\section{Recommended Citation}

Aronson, Jay D. (2017) "Preserving Human Rights Media for Justice, Accountability, and Historical Clarification," Genocide Studies and Prevention: An International Journal: Vol. 11: Iss. 1: 82-99.

DOI:

http://doi.org/10.5038/1911-9933.11.1.1441

Available at: https://digitalcommons.usf.edu/gsp/vol11/iss1/9

This Symposium on the State of the Field is brought to you for free and open access by the Open Access Journals at Digital Commons @ University of South Florida. It has been accepted for inclusion in Genocide Studies and Prevention: An International Journal by an authorized editor of Digital Commons @ University of South Florida. For more information, please contact digitalcommons@usf.edu. 


\section{Preserving Human Rights Media for Justice, Accountability, and Historical Clarification}

\section{Acknowledgements}

This work was supported by grants from the MacArthur Foundation, Oak Foundation, and Humanity United. The author would like to thank Yvonne $\mathrm{Ng}$ for her critical comments and collegiality throughout the drafting of this article. He would also like to thank Wendy Betts and Jarrett Drake for their feedback on later versions. 


\title{
Preserving Human Rights Media for Justice, Accountability, and Historical Clarification
}

\author{
Jay D. Aronson \\ Carnegie Mellon University \\ Pittsburgh, Pennsylvania, USA
}

\section{Introduction}

Archives are not neutral. They exert social and political power. ${ }^{1}$ This power is a product both of the content of an archive and the norms and assumptions that guide its curation. It has traditionally been deployed on behalf of the elite to preserve the political order. ${ }^{2}$ When used in historical scholarship, archives make certain aspects of the past visible while obscuring others, whether through selective culling or selective analysis. ${ }^{3}$ Over the past few decades, however, archivists and historians have increasingly recognized that the power of archives can be redeployed to advance the cause of governmental accountability, human rights, and social justice. ${ }^{4}$

At the same time, there has also been a move to preserve more than just the documents and records of governments, businesses, the wealthy, and the famous. Archives and archiving projects are increasingly concerned with preserving the physical traces that ordinary people leave behind, including their diaries, letters, and records of commerce, activism, and community organizing. ${ }^{5}$ This broadening of scope not only breaks down the hierarchies of knowledge that have been critiqued by social theorists, historians, and archivists alike, but also makes possible the telling of history from multiple perspectives. ${ }^{6}$

Rather than focus exclusively on the development, justification, and implementation of policy by the elite, we can see how such policies actually affected the lives of ordinary people. ${ }^{7}$ We can hear the voices of those who are silenced in contemporary society because they are not viewed as important to listen to (e.g., female homemakers, subsistence farmers, unskilled labor, the LGBTQ community, or the racial and ethnically marginalized), and learn more about their lives. ${ }^{8}$ The shifting conception of the archive's social value has been paralleled by another development: the dramatic expansion of the role of the Internet, computers, and mobile devices in human communication and the corresponding requirement of archivists to respond to this trend. ${ }^{9}$

This article will explore the convergence of these trends in the intentional, third party preservation of images and video of human rights abuse or war crimes created by witnesses, victims, or perpetrators and shared via social media platforms. ${ }^{10}$ It is meant to provide a broad introduction for practitioners, advocates, journalists, and policy makers who have not had formal training in this domain and are working outside of institutions with well-developed archival practices. It explains why preservation of this content is crucial and seeks to help human rights practitioners

${ }^{1}$ Randall C. Jimerson, Archives Power: Memory, Accountability, and Social Justice (Chicago: Society of American Archivists, 2009); Michel-Rolph Trouillot, Silencing the Past: Power and the Production of History (Beacon Press: Boston, 1997).

${ }^{2}$ Joan M. Schwartz and Terry Cook, "Archives, Records, and Power: The Making of Modern Memory," Archival Science 2 (2002), 1-19.

${ }^{3}$ Ibid.; Trouillot, Silencing the Past.

${ }^{4}$ Jimerson, Archives Power; Verne Harris, Archives and Justice: A South African Perspective (Chicago: Society of American Archivists, 2007); Kirsten Weld, Paper Cadavers: The Archives of Dictatorship in Guatemala (Durham: Duke University Press, 2014).

${ }^{5}$ Catherine Hobbs, "The Character of Personal Archives: Reflections on the Value of Records of Individuals," Archivaria 52 (2001), 126-135.

${ }^{6}$ Mark A. Greene, "The Power of Meaning: The Archival Mission in the Postmodern Age," The American Archivist 65 (2002), 42-55.

${ }^{7}$ Hobbs, The Character of Personal Archives.

${ }^{8}$ Susan Tucker, "Tacitly the Work of Women: Personal Archives and the Public Memory of Families," in Perspectives on Women's Archives, ed. Tanya Zanish-Belcher and Anke Voss (Chicago: Society of American Archivists, 2013).

${ }^{9}$ See, e.g., The Digital Curation Centre http://www.dcc.ac.uk/; Digital Preservation Coalition: http://www.dpconline. org; COPTR: http://coptr.digipres.org/Main Page; Library of Congress Digital Preservation Resource: http://www. digitalpreservation.gov/; Open Preservation Foundation: http://openpreservation.org/; Preserving (Digital) Objects with Restricted Resources (POWRR): http://digitalpowrr.niu.edu/.

${ }^{10}$ For the sake of clarity and space, this article will not address text-based Internet media, such as tweets, blogs, or other social media postings, or historical video that is stored or archived in a non-digital format. 
embed preservation into the process of media collection and human rights documentation without assuming that these organization will want, or be able, to implement a full-scale archiving operation. To borrow a phrase routinely repeated in investigations of the ethics and practice of preservation, this study will provide more questions than answers. ${ }^{11}$

\section{The Duty to Preserve}

Video and images of human rights abuse and war crimes are constantly at risk of disappearing from the public domain. The creator or uploader could decide that the risks of posting such material are too great to justify its continued existence online (i.e., that its existence puts individuals or communities at risk); a nefarious actor could threaten them and demand that they take the content down or close their account all together; or they could become overwhelmed by the publicity they are receiving from the media or the public. ${ }^{12}$ Content can also be taken down by the hosting company because it violates community standards, the end user agreement, or copyright law. This might occur because viewers of the content flag it as violent, sexual, or inflammatory in nature, or if copyrighted music or video are used to supplement the creator or uploader's message or point of view. Those with a vested interest in rendering the content of the media invisible will often deploy these strategies in order to facilitate its disappearance. Additionally, private companies may shut down the accounts of blatant human rights violators in order to make it harder for them to get their message out, which has the unintended consequence of hiding evidence of their activities from human rights investigators. The uploader's account might be hacked by nefarious actors and either taken offline entirely or stripped of certain content. This threat of disappearance provides all the more reason for smaller organizations to preserve a copy of their content regardless of whether or not they choose to share it, and for larger organizations to provide support and resources to these groups in this endeavor. ${ }^{13}$

No matter what the cause, the disappearance of content relevant to human rights investigations and conflict monitoring occurs on a regular basis. ${ }^{14}$ For those who believe in the inherent value of human rights documentation, there is a pressing duty to preserve this content for use in humanitarian, justice and accountability, and historical investigations. This duty is shared by individuals and institutions whose missions are explicitly human rights-oriented and who are capable of doing so in a safe and secure way, as well as the privately operated platforms that serve as de facto public forums for media that clearly depict human rights violations and war crimes. This preservation, of course, must be done with the explicit intent to protect and promote human rights and has precedent in the way that the preservation of child pornography is handled by these platforms. WITNESS, the Human Rights Center at UC-Berkeley and other groups have been discussing the idea of an evidence locker-a repository for human rights media that will likely be taken down by content platforms-but numerous questions remain about whether it should be done, and if so, who would house and govern this archive if maintained separately from other content. One challenge in this context that will require additional ethical deliberation is the reality that the preservation process will directly undermine the decision of particular creators or uploaders to return their content to the private domain for legitimate reasons.

\section{The Importance of Images and Video}

The creation of video or images of human rights abuse or war crimes may be accidental or explicitly for the purposes of documenting wrongdoing. In some cases, the creator shares this media directly online, and in others local or international content aggregators operating social media channels

\footnotetext{
${ }^{11}$ See, e.g., Elena S. Danielson, The Ethical Archivist (Chicago: Society of American Archivists, 2010), who provides a list of the questions her study generated at the end of each chapter of her book.

${ }^{12}$ David Crunelle, "The Art of Being in the Wrong Place At the Right Time: Behind the Scenes of Social Media Newsgathering," accessed September 19, 2016, https://medium.com/@emhub/the-art-of-being-in-the-wrong-place-atthe-right-time-behind-the-scenes-of-social-media-3ee558630e93\#.7ls6u8wln.

${ }^{13}$ Yvonne Ng (WITNESS), personal communication, May 24, 2016.

${ }^{14}$ In my own work on videos from Syria and Ukraine, between $20-50 \%$ of the videos originally identified on public platforms are no longer publicly accessible.
} 
that focus on specific issues or regions post it. The value of such material in improving our understanding of these events has been amply demonstrated in the Syrian conflict, unrest and demonstrations in Ukraine, episodes of violence in Nigeria, and situations of police brutality in the United States (to name just a few diverse cases).

Video and images often compliments official narratives and press accounts of an event or situation, adding detail and nuance. At other times, they directly rebut certain factual claims and contradict particular narratives. However it is important to remember that images and video are framed - the viewer can only see what the cameraperson chooses to focus on or the editor choses to include in the final cut. One advantage of citizen media is that a given event is often filmed from multiple locations, allowing for its multi-perspectival reconstruction. The availability of numerous accounts of an event can hopefully shed light on the limitations of any one view. It can also provide a richer accounting of what happened by expanding the amount of information that can be gathered about an event, as well as what happened immediately before and after it.

It is also important to note that people only record and share certain kinds of events with their cameras - usually dramatic moments taking place in public or semi-public places, and they only post certain kinds of content on the Internet. Thus, crimes like intimate partner violence (IPV) and labor law violations are generally not captured on video. There are notable exceptions to this trend-see, e.g., the surreptitious investigative work of Videre est Credere in the labor domain; or incidental capture of IPV by closed circuit surveillance systems - but at the moment, they are few and far between. Further, some crimes require documentation of systematic, ongoing violations over time. While the first few instances of a crime may be captured by witnesses or victims, perpetrators will eventually become aware of their actions and will alter their behaviors accordingly.

\section{Human Rights Archives}

There is by now a well-developed literature on crucial role that archives can play in historical clarification and justice and accountability efforts in the aftermath of human rights abuse and war crimes-particularly when it comes to preserving the administrative records of wrongdoers. Louis Bickford was among the first human rights advocates to voice the "archival imperative."15 In 1997, the UN Commission on Human Rights articulated the core principle that human rights abuse victims' right to know necessarily implies the preservation of archives and, further, that every effort should be undertaken both to prevent destruction of relevant material and to inform and protect those individuals whose names appear in the records. ${ }^{16}$ Such actions were seen as key to ending impunity. Further, the International Council of Archives 2009 report on archives and human rights highlighted the crucial work that archives can do in societies transitioning from repressive regimes to democracy. ${ }^{17}$

These sources make it clear that because human rights abusers and war criminals could erase evidence of their wrong-doing by destroying or hiding their records, it is incumbent upon the human rights community to prioritize preservation of these records before they disappeared. ${ }^{18}$ The most obvious reason to preserve the records of human rights abuse and war crimes is the need to hold perpetrators responsible for their misdeeds, to acknowledge the suffering of victims, and to begin the process of healing societies torn apart by violence and suffering. This requires knowing what happened to the extent that it is ever possible to do so.

\footnotetext{
${ }^{15}$ Louis Bickford, "The Archival Imperative: Human Rights and Historical Memory in Latin America's Southern Cone," Human Rights Quarterly 21, no. 4 (1999), 1097-1122.

${ }^{16}$ Louis Joinet, “The Administration of Justice and the Human Rights of Detainees Question of the Impunity of Perpetrators of Human Rights Violations (Civil and Political)," E/CN.4/Sub.2/1997/20 (1997).

${ }^{17}$ Antonio González Quintana, "Archival Policies in the Protection of Human Rights" (International Council on Archives, 2009). The International Council of Archives also has produced a draft set of principles for archivists involved in human rights work, but this document has not been finalized as of the publication of this article. International Council on Archives Human Rights Working Group, "Basic Principles on the Role of Archivists in Support of Human Rights (Draft)," accessed June 9, 2016, http://www.icarchives.webbler.co.uk/15999/news-and-events/basic-principles-on-therole-of-archivists-in-support-of-human-rights-give-your-opinion.html.

${ }^{18}$ Harris, Archives and Justice; Weld, Paper Cadavers.
} 
But Bickford makes the case for preservation on numerous other grounds as well: first, the need to disprove claims by revisionists who almost always emerge to deny, or at least minimize, crimes against humanity. Second, archives allow "future generations, from historians to family members, to thoroughly investigate what happened and reach their own conclusions." ${ }^{19}$ Third, it is impossible for any justice and accountability effort to provide a complete picture of the past because time, resources, mandates, political imperatives, and imagination are always finite. While these institutions might produce significant truth or clarification, there is always "more to be learned about what occurred, especially, in terms of human rights violations, within the inner-workings of authoritarianism, inter-regional and international aspects of military rule, and contemporary human rights movements." 20

These endeavors all contribute to determining what is known and not known in a given society, whose perspectives play into the development of collective memory, and what resources members of society have to question and challenge the historical accounts that structure the reconstruction of their world. ${ }^{21}$ But archives are not simply records of what happened. They are symbolic, and constitutive, of what kind of knowledge is valued and what kinds of knowledge projects are possible. As such, they possess power that exceeds the way they are deployed by any given interested party.

At the same time it is important to recognize the numerous hazards of collecting large amounts of sensitive information and storing it in one or a few places. In the context of videos and images, there are obvious concerns regarding the safety and security of creators and those portrayed in them, as well as the presumption of innocence of the individuals who are accused of, or appear to be committing, crimes in images or video. Large-scale preservation of digital content begs the question of who owns this information and what can be done with it. How much control should content creators and social media uploaders retain over the preservation and use of their content by third parties - even those with the purest motives and best of intentions - when it has significant historical, political and legal value? Should the wishes and privacy of victims depicted in human rights related video be privileged over the important social goal of preserving the historical record? Should the goal of preservation supersede the desire of such individuals to take down and privatize images or videos that were publicly available for a period of time-even when we know that access to information often fails to lead to justice or accountability in politically contentious situations? Should collected audiovisual material related to human rights abuses and war crimes be made public or kept private, and if kept private, how should access and use be governed? What rights do the accused/perpetrators have when they can be seen in videos or images committing what appear to be crimes and human rights abuses?

On a related note, large international justice organizations now have even greater potential to extract preserved information from smaller more regional organizations and use it to pursue their desired ends. Sometimes these ends are at odds with, or at least not the priorities of, the groups or individuals who document conflict and human rights violations at the local level. Rather, they often reflect the normative frameworks and imaginaries of international institutions and the individuals who staff them..$^{22}$ Finally, the archival imperative rests on the positivist notion that the preservation of information about human rights violations and war crimes is an inherently good thing, and that its use will lead to positive outcomes for affected individuals, communities, and societies. Recent scholarship, including the work of archivist Verne Harris and writer David Rieff, suggests that this may not always be the case. ${ }^{23}$ It is not possible to give this particular issue

${ }^{19}$ Bickford, The Archival Imperative, 1099.

${ }^{20}$ Ibid.

${ }^{21}$ Graham Stinnett, Rebel Collectors: Human Rights and Archives in Central America and the Human Rights Commission of El Salvador and the Resource Center of the Americas, 1978-2007 (Winnipeg, Manitoba: University of Manitoba and University of Winnipeg, 2010).

${ }^{22}$ Elena Baylis, “Tribunal-Hopping With the Post-Conflict Justice Junkies,” Oregon Review of International Law 10 (2008), 361-390.

${ }^{23}$ Verne Harris, "Claiming Less, Delivering More: A Critique of Positivist Formulations on Archives in South Africa," Archivaria 44 (1997), 132-140; David Rieff, In Praise of Forgetting: Historical Memory and Its Ironies (New Haven: Yale University Press, 2016). 
the space and consideration it deserves, but it is crucial to at least recognize the assumptions and normative frames that undergird this analysis.

\section{Human Rights Media Preservation Landscape}

A great deal of human rights-related media is being collected and stored outside of traditional archives or libraries by journalists and human rights activists. Sometimes the individuals and organizations doing this work have training in archiving or are being advised by professional archivists, but this is not always the case. Many journalists, especially those employed by mediacentric organizations like Storyful, have well-developed practices that are tied into their business models, but there is no default professional code of conduct that regulates preservation and sharing of human rights-related content and it would be difficult to create one.

On the activist side, the independence of what are sometimes called community archives from elite actors and dominant institutions may reflect the marginalization and powerlessness of those involved in the creation and collection of materials, or it may reflect a conscious decision to work outside of power structures that are perceived as discriminatory or disempowering. ${ }^{24}$ There is increasing effort in the archivist profession, however, to work directly with community members to help them document and preserve their own histories. ${ }^{25}$ There is also a robust tradition within the archiving community of conceiving of human rights archives as any material that can illuminate injustice,notjustadministrativerecordsorofficialdocuments, and alsoframing principlesand practices in terms of their social impact rather than the purely technical principles of archival science. ${ }^{26}$

While it would be valuable if professional archivist with significant experience in human rights documentation were available to advise every human right media preservation effort that requested such support, this is unlikely to occur given the number and diversity of such endeavors and the barriers that often separate lay and professional communities. That said, archivists can still work together with the human rights community and front-line journalists to play a vital role in preserving human rights related digital content in a way that is mindful of the technical, legal, ethical, political and cultural challenges in this process, and that privileges the needs and desires of human rights abuse victims. ${ }^{27}$

\section{Archiving Human Rights Media}

There are many kinds of human rights media archiving efforts. First is the long-term preparation and storage of proprietary content by the creator or an organization/repository selected by the creator as the recipient of such content. Second is the acquisition and storage of content found on public social media and the Internet, or shown on live-streaming services such as Periscope, Meerkat, Facebook, or Twitter. And third is the collection of material that doesn't fit neatly into either of these categories: namely that sent privately on social media or through sharing applications such as Snapchat, WhatsApp, Yik Yak, and Telegram. In many cases, media from this category are widely circulated even if they are never made explicitly public on the open Internet. A fourth kind of archiving involves the surreptitious collection of media by an unauthorized source who has access to it for purposes of whistleblowing. While these archives are not initially public, they may either be captured and made public by the opposition or leaked by individuals who want the world to know what is happening. The Caesar photos from Syria and audiovisual and textual resources regarding U.S. military actions provided to Wikileaks by Chelsea Manning are two examples of this phenomenon.

The focus of this article will be primarily on the second and third form of archiving. This is partly because self-preservation of materials fits squarely with the traditional model of archiving,

\footnotetext{
${ }^{24}$ Michelle Caswell, "Toward a Survivor-Centered Approach to Records Documenting Human Rights Abuse: Lessons From Community Archives," Archival Science 14, no. 3-4 (2014), 307-322. 
and partly because the non-governmental organization WITNESS has already produced an excellent guide for advocates to archive their own materials. ${ }^{28}$ That said, there are many areas of overlap (the WITNESS guide is referenced several times here), and there are many organizations that archive both their own content and found material, so this document can be read in parallel with that guide. The bottom line in both cases is that preserving media requires technical skill and a willingness to put time and labor into setting up the necessary infrastructure with thought and care. Cutting corners to save time in the short run will often lead to significant expenditures of time, or worse, loss of data or data integrity, in the long-term. Both also include significant legal and ethical questions that may require counsel and definitely require conscientious deliberation within the archiving institution. Further, it is crucial to recognize that while preserving evidence for use in humanitarian response, long term justice and accountability efforts, and historical clarification is important, the safety of creators, those depicted in the media, and their families is paramount. As WITNESS notes:

Inherent in video's power to convey an individual story is the potential for a video to impact the safety, dignity, and privacy of individuals and communities captured in the footage. A video of sexual assault, for example, has the potential to shame, re-victimize, and endanger the abused individual. Widely circulated footage of human rights defenders could make them targets of arrest or violence by repressive governments. Testimony of a police officer describing corruption among his superiors could put that officer at risk of losing his job or worse. ${ }^{29}$

It is important to note that a crucial source of evidence in many human rights investigations is media created by perpetrators, rather than victims, eyewitnesses, or rights advocates. This content raises additional questions that must be carefully considered as part of the archiving processsuch as whether to make this material public, how to protect the privacy of victims depicted in the media, and how to preserve the due process legal rights of those who are depicted committing potential crimes or abuses.

\section{Appraisal}

The first step of any preservation effort takes place before any content is collected: the preserving organization or individual must decide what its purpose is and what the scope of its collection will be-i.e., what it is going to collect, what it is not going to collect, how it makes that assessment for specific content, how the collection will be used, and who will have access to it. The answers to these questions may evolve over time, but it is crucial that any preservation project begin with a clear mission in mind. This mandate may be all encompassing, such as the Syria Justice and Accountability Center's desire to collect and preserve documentation of any type (including hundreds of thousands of videos) of all "violations of human rights, humanitarian, and international criminal law in Syria," regardless of perpetrator, "in order to facilitate transitional justice and accountability efforts." ${ }^{30}$ Or, it may be narrowly tailored, such as WITNESS's new effort to collect, analyze, and contextualize video of hate crimes against transgender people in the United States. ${ }^{31}$

The storage method chosen and availability of human labor will at least in part determine what media is actually kept. If either are limited, the preserving organization may have to be extra selective about what to preserve and what not to. An organization with limited storage or labor might decide to keep only video from established sources or close collaborators in original, raw format and ignore anything that has been edited or is available on social media. Organizations that

${ }^{28}$ WITNESS, "Activists' Guide to Archiving Video," accessed June 15, 2016, https://archiveguide.witness.org/.

${ }^{29}$ WITNESS, “Ethical Guidelines: Using Eyewitness Videos in Human Rights Reporting \& Advocacy," accessed June 13, 2016, https://library.witness.org/product/video-as-evidence-ethical-guidelines/, 4.

${ }^{30}$ Syria Justice and Accountability Center, "Collect and Preserve Documentation," accessed September 19, 2016, https://syriaaccountability.org/what-we-do/.

${ }^{31}$ Karen Stevenson, “Curating Eyewitness Videos for Data on Transphobic Violence," WITNESS (June 2016), accessed September 19, 2016, https://lab.witness.org/curating-eyewitness-videos-data-transphobic-violence/. 
have access to large amounts of storage, and a lot of labor, might elect to collect everything with little initial evaluation, and then go back at a later date to filter out extraneous results, authenticate the media that is kept, and evaluate its content. All are logical decisions that are based on mission and resources. In a world of limited resources, significant value can be gained when organizations work together in the mode of "collaborative collecting" to secure as complete a record of a situation as possible. ${ }^{32}$

\section{Acquisition}

Once the scope and mission of the effort is specified, the next step is to determine how to acquire of the most authentic version of the relevant media possible. The original, complete, unedited file is preferred, but this will often be impossible when video or images shared via social media are involved. If the creator of the media is known and can be contacted, the preserver should consider doing so, but only after carefully considering the risk associated with reaching out to the individual. They should ask for as much background about the circumstances in with the media was filmed as possible-especially date, location, and what they captured in the video. If possible, the archiving organization should request the master copy, and, if the video has been edited, also consider collecting the original, raw sources of the selections that were brought together.

The preserving organization should also try as best as it can to request permission to store, utilize, and share the image or video. This conversation should also directly address issues of longterm ownership and control of the material, which is discussed below. The organization should be as explicit as possible about how the media will be stored and all the potential uses to which it may be put, and also find out whether the creator would be willing to be contacted in the event that the media is used for investigatory, legal, or historical purposes. The organization should also ask whether the creator would like to be credited in any way if the content is used, and if so, how. This can be a monumentally large and difficult process when dealing with large volumes of video, and impossible when a creator or uploader cannot be discerned. In addition to the issue of personal harm and violation of privacy, those engaged in preservation must think carefully about what to do when content they have preserved from the Internet is taken down or goes private. Do organizations have a duty to delete this material from their collections, preserve it for posterity, or endeavor to strike a balance-however imperfect-between the two? There is no clear answer to this question. ${ }^{33}$

Whether or not the creator can be contacted, the organization should document all aspects of the acquisition process (time, date, source, location, etc.), as well as any preservation metadatai.e., a record of any action performed on the media by the archive, including: changes in format to ensure continued accessibility; information about hardware used in storage process; usage data; and rights information. There are many guidelines for preservation metadata, including the Library of Congress's PREMIS standard. ${ }^{34}$ Without such documentation, assurance of chain of custody and the ability to authenticate a video will be compromised moving forward. ${ }^{35}$ In the case of publicly available/shared content for which it is difficult or impossible to contact the creator, the first known version, in the highest resolution available, should be acquired. In either case, acquisition should involve the collection of all public metadata available at the time of collection, not just the media itself, and a record of how the resource looked when it was acquired (either in the form of a screenshot or preservation of $\mathrm{html}$ code). This package should then be cryptographically hashed (given a unique alphanumeric identifier produced through a computational process and time-stamped) using a trusted source to ensure their authenticity and makes it possible to detect subsequent tampering. ${ }^{36}$

\footnotetext{
${ }^{32}$ Danielson, The Ethical Archivist, 53.

${ }^{33}$ WITNESS, Ethical Guidelines: Using Eyewitness Videos.

${ }^{34}$ Library of Congress, "PREMIS," accessed June 15, 2016, http://www.loc.gov/standards/premis/.

${ }^{35}$ WITNESS, "Activists' Guide to Archiving Video," accessed June 15, 2016, https://archiveguide.witness.org/.

${ }^{36}$ For an explanation of cryptographic hashing, see: Enrique Piracés, "Trusted Timestamping," accessed September 19, 2016, https://www.rightslab.org/vault/faq.php\#Trusted Timestamping.
} 
Courts, tribunals, and other fact-finding bodies will differ in exact requirements for collection of metadata and formats, so it is best to collect as much information as possible when acquiring human rights-related media and store it in the most flexible database possible. Preservation specialists and human rights practitioners have discussed the merits of adopting a single preservation policy for the human rights community (or at least those human rights organizations that are hooked into dominant internationally-oriented networks), such as one based on the International Criminal Court's eCourt Protocol (which lays out the evidentiary standards - and therefore many preservation requirements - for the use of electronic evidence in its legal proceedings), but no such action has been taken at the time of the publication of this article. ${ }^{37}$ Whether the content is privately collected or gathered from public sources, as noted above, it is imperative to preserve as much original metadata as possible and record all modifications made to the file once it enters your possession.

Many human rights practitioners who specialize in documentation, including those who run Amnesty International's Citizen Evidence Lab, are using a tool called VideoVault for acquiring online content..$^{38}$ It is available both as a standalone web application in a browser, or as an extension for the Google Chrome browser that automatically preserves a video and all relevant additional information and metadata with the click of a button. It then sends this data to the user as a preservation package to be stored in a location selected by the user.

Storage

Acquired media should be stored in the most secure way possible. There is no single solution to this task. The best storage method will be determined by the situation and the resources available to the individual or institution acquiring the media. In all cases, though, efforts should be undertaken to ensure the security of the system, and that it is at least minimally redundant (i.e., more than one copy is kept). The Responsible Data Forum (RDF) recently published its first handbook, which contains a useful chapter on archiving and preservation of digital content in human rights and humanitarian contexts. ${ }^{39} \mathrm{RDF}$ suggests that organizations that will have difficulty creating a "home for healthy data" ${ }^{40}$ should consider partnering with one of the established human rights archives connected with a major university or large NGO, including Open Society, Duke University, or Columbia University. Many human rights organizations already rely on these institutions to archive their finished work products and inactive business records. Amnesty International, Human Rights Watch, and Physicians for Human Rights, for instance, deposit many of their materials in Columbia University's Archive. ${ }^{41}$ Duke University's archives have an extensive collection of Latin American human rights-related material as well as the collection of the International Center for Transitional Justice. ${ }^{42}$ The Open Society Archives contain extensive documentation of human rights struggles in the former Communist countries of Central and Eastern Europe, including over 11,000 hours of audiovisual material. ${ }^{43}$

${ }^{37}$ Enrique Piracés and Jay D. Aronson, "Human Rights Media Central Workshop Summary Report" (October 2015), accessed June 15, 2016, http://www.cmu.edu/chrs/documents/HRMC-Meeting-Report.pdf; International Criminal Court, "eCourt Protocol," accessed June 15, 2016, https://www.icc-cpi.int/iccdocs/doc/doc1695618.pdf.

${ }^{38}$ VideoVault is being developed by Enrique Piracés, my colleague at the Center for Human Rights Science at Carnegie Mellon University. He is carrying out this work independently of the center and the university as a public service to the human rights community. He has no financial stake in the software. See: Enrique Piracés, "VideoVault," accessed April 24, 2017, https://www.bravenewtech.org.

${ }^{39}$ Responsible Data Forum, "Closing a Project: Archiving and Preservation of Content," accessed June 15, 2016, https:// responsibledata.io/resources/handbook/chapters/chapter-03-closing-a-project.html. Other archival models exist as well, including the International Organization for Standardizations' Open Archival Information System (http://www. iso.org/iso/catalogue detail.htm?csnumber=57284), and the National Digital Stewardship Alliance (http://www.

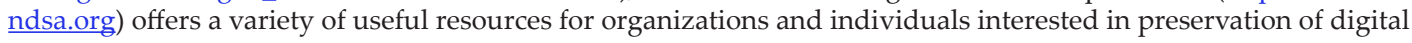
materials.

${ }^{40}$ Responsible Data Forum, "Managing Data: Setting Up the Data Infrastructure," accessed June 15, 2016, https:// responsibledata.io/resources/handbook/chapters/chapter-02-managing-data.html\#a-home-for-healthy-data.

${ }^{41}$ Columbia University Libraries/Information Services, Center for Human Rights Documentation \& Research, accessed June 16, 2016, http://library.columbia.edu/locations/chrdr/archive collections.html.

${ }^{42}$ International Center for Transitional Justice, accessed February 24, 2017, https://www.ictj.org/.

${ }^{43}$ Vera \& Donald Blinken Open Society Archives, accessed June 16, 2016, http://www.osaarchivum.org/archives. 
Yet, this is clearly not a viable approach for smaller organizations that lack trust in larger institutions to safeguard their material or fear that they will lose control of their content if it is under the care of a third-party. Further, the initiatives above tend to follow a more traditional archiving model, in which completed work products and inactive business records are processed and stored. These organizations tend not to rely on third-party repositories for the immediate storage of material being collected for future analysis and use. ${ }^{44}$ Further, in most cases, organizations that preserve content will potentially be in violation of terms of service of the social media and Internet platforms where they initially discover the content, which will likely cause problems when negotiating with larger archiving institutions.

For organizations that do not wish to enter into any form of partnership, but want to store their material off site, numerous cloud-based services (e.g., Box, Dropbox, Apple iCloud, or Amazon) provide simple, relatively low-cost, and relatively secure ${ }^{45}$ storage solutions. Before uploading material to these services, it is important for organizations and activists to understand that they might be legally required cooperate with law enforcement or other state agents if formally asked to provide access to content. Such services are also liable to hacking and other forms of password theft. It is also important to recognize that the cloud is really just somebody else's server. It does not denote a magical, mythical $100 \%$ dedicated and secure repository, despite the marketing efforts by large companies that provide such services. For web-based material, the Internet Archive (archive. org), which includes perpetual storage on their secure servers for no cost, is another viable option. The Internet Archive also serves as the backend storage site for the digital content of the major academic archiving organizations just mentioned, and will soon be compatible with VideoVault. They also offer their own (paid) subscription-based tool and system called Archive-It that offers more control over content once it is uploaded. It should be noted that Archive-It is not optimized for video and is generally used by universities and institutions that have a dedicated, specialized archiving staff.

Finally, media can be stored on a hard drive, or a non-networked server, although care must be taken to ensure redundancy and guard against physical theft or destruction of the storage device. As strategies for ensuring the continued health of stored material, WITNESS recommends making at least two copies (preferably three), checking files regularly, controlling access, and regularly updating the storage mechanism to keep up with changing technologies. ${ }^{46}$ Encryption should be used if transmitting content to a secure location, but files should be stored unencrypted if at all possible to prevent problems accessing the media in the future.

Organization/Cataloging and Content Tagging

Collections of preserved video and images have little value if their content cannot be easily determined and searched. The starting point for all media cataloging efforts is the metadata collected at time of acquisition, including information provided by sources of directly acquired content, technical metadata, and anything related to chain of custody. Catalogues should also include keywords, a basic description of what can be found in the media, what rights restrictions might be placed on the content, and whether the identities of any of the people depicted in the video need to be protected. The richer the catalogue for any given collection, the more value it has to human rights advocates, researchers, and historians. ${ }^{47}$ There is, of course, an inherent tradeoff in the cataloguing process that archivists have been discussing and debating for a long time: cataloging is very labor intensive, can be highly subjective and biased, and every moment spent extracting information from a one resource means that another resource might languish unnoticed or uncatalogued..$^{48}$

\footnotetext{
${ }^{44}$ Yvonne Ng (WITNESS), personal communication, May 24, 2016.

${ }^{45}$ Cloud storage providers offer a wide variety of security levels, ranging from simply password protection to measures that governments feel comfortable using for sensitive information.

${ }^{46}$ WITNESS, “Store: Introduction," accessed June 16, 2016, https://archiveguide.witness.org/store/introduction.

${ }^{47}$ WITNESS, “Catalog: Introduction,” accessed June 16, 2016, https://archiveguide.witness.org/catalog/introduction.

${ }^{48}$ Mark A Greene and Dennis Meissner, "More Product, Less Process: Revamping Traditional Archival Processing," The American Archivist 68 (2005), 208-263.
} 
Although it is unlikely that an archiving institution or human rights group will have the capacity to extract all relevant information from a collection (this, after all, is generally not the task of an archive), the following types of information can at least conceivably be added to a catalogue by analysts working with the archiving institution or using the collection for research or accountability purposes:

- Using geolocation tools available on Citizen Media Lab's Toolbox, it is often possible to determine the location of a filmed event by matching features using services like Google Earth, Google Street View and satellite imagery.

- It is sometimes possible to determine the date and approximate time of day using shadows, weather, sun position, and other climactic and clues in the footage.

- Perpetrators can sometimes be identified (either individually or at the group level) based on uniforms/clothing, weapons, vehicles, and other physical possessions provided they can be matched to verified footage or images elsewhere.

- Approximate counts of people, whether victims, participants in events or bystanders can be determined within the region that is captured in the footage.

- Types of weapons, vehicles, tools, and other possessions or other implements can be discerned. This information can help link particular actors to events as supporters even if they are not physically present.

- Forensic clues about the incident can sometimes be determined using images of wounds, blood splatter patterns, position of victim, and overall view of crime scene.

- Patterns of activity can sometimes be detected when there are multiple videos or images from a particular situation - this can be crucial evidence for a claim that a particular action was part of an orchestrated plan and not a one-off mistake by a "bad apple."

The Center for Human Rights Science at Carnegie Mellon is currently developing semi-automated methods of categorization, tagging, and information extraction from videos and images that lack metadata, but for the moment this work is generally done manually. ${ }^{49}$

\section{Authentication}

Once media has been acquired, stored, and catalogued, it must be authenticated before it can be used for legal, scholarly, or advocacy purposes. ${ }^{50}$ Organizations preserving video and images for human rights documentation purposes need to know whether the material they have collected actually depicts what it is claimed to show. Authentication is the first step in the longer process of verifying whether the claim made about it is true or not. In other words, a video could actually be authentic (i.e., filmed at the time and place claimed and not altered in any way) but still not be a full, truthful account of what happened there (i.e., it could leave out important parts of a scene or not show the event in its entirety). However, if a video is not filmed at the time and place claimed, or is altered in certain ways, there is no way it can be truthful account of what happened at a different time or place. Such non-authentic videos should not be discarded, however. They may be crucial to understanding how particular parties are seeking to alter understandings of a crime or event.

A robust set of practices has emerged around the authentication and verification of human rights media in recent years. The Verification Handbook, published by the European Journalism Centre, provides instructions and case studies for the authentication of video and images in a journalistic or emergency response context. ${ }^{51}$ Amnesty International's Citizen Evidence Lab provides step-by-step tutorials, case studies, test exercises, and an updated list of tools for human

\footnotetext{
${ }^{49}$ Jay D. Aronson, et al., "Video Analytics for Conflict Monitoring and Human Rights Documentation" (Pittsburgh: Carnegie Mellon University Center for Human Rights Science, 2015).

${ }^{50}$ Craig Silverman, Lies, Damn Lies, and Viral Content: How News Websites Spread (and Debunk) Online Rumors, Unverified Claims, and Misinformation (New York: Tow Center for Digital Journalism/Columbia Journalism School, 2015).

${ }^{51}$ Craig Silverman (ed.), The Verification Handbook (Maastricht, the Netherlands: European Journalism Center, 2013) is available online at http://verificationhandbook.com/ in English and several other languages.
} 
rights researchers faced with verifying content. ${ }^{52}$ The site also contains a valuable reading list regarding authentication and media in the human rights context.

Christoph Koettl, Citizen Evidence Lab's founder, has produced a framework for reviewing and verifying human rights related media. This framework begins with metadata review. Koettl provides an updated list of free and open source tools for reviewing video and image metadata in the Citizen Evidence Lab Toolbox. ${ }^{53}$ When video or photograph is acquired in its original, unprocessed format, metadata and image analysis can be used to determine when and where the footage was shot, on what equipment, and whether it has been modified in any way. ${ }^{54}$ Unfortunately, when a video or image is uploaded to social media platforms, its technical metadata is replaced by metadata created when it is processed for streaming. This public metadata can tell you when was uploaded, and sometimes from where, but it has limited value for authentication.

In addition to metadata review, the Citizen Evidence Toolbox provides several other verification methods, including using reverse image search to look for the earliest available posting of a particular image or video. Koettl highlights several cases (including examples from Nigeria, Syria, and Palestine, among others) in which content from one time or place was passed off as evidence of human rights abuses in another time or context. Such deception can be intentional (i.e., done explicitly to deceive or falsely accuse an individual or agency of a crime) or, especially in the age of viral video and online activism, unintentional (i.e., passing along incorrect information in the hope of improving a situation, or misreading the context of a particular piece of media).

Other attributes of the source can be helpful in determining the extent to which it can be trusted. For instance, a video or image is released of a human rights violation in a conflict situation by a person who has a long history of posting either from that location or about that location might be accorded more credibility than another image or video posted by someone (or some organization) who either just opened a social media account, or has only posted from or about other locations before. Further, a video or image from someone who is deeply embedded in social networks in the place that is the subject of the report may be more credible than one posted by an individual or organization that is not well-known in the community. These are not definitive markers of veracity, of course, but provide additional information that can be used in such a determination.

Before images or videos are used in court or for advocacy purposes, subject matter and regional specialists should be consulted to verify interpretation and provide historical or cultural context, although this is not the primary responsibility of the organization or individual preserving them. They may also need to be examined by technical experts who have access to proprietary (and expensive) software used to identify edited or manipulated media. ${ }^{55}$ Further, as Koettl and others note, video and images do not speak for themselves, however visually compelling they may be. Media will both strengthen a case, and be strengthened, through integration with information from other sources, including eyewitness accounts, satellite data, military reports, official government documents, NGO findings, and other forms of evidence. Such corroboration is already a core practice of human rights documentation, and should continue even as digital evidence becomes more prevalent.

\section{Ethical and Legal Considerations}

This section will address some of the main ethical and legal challenges associated with the preservation of human rights-related media-including the notion that preservation of evidence of human rights violations is always an inherently good thing to do. There are numerous frameworks one could use to address these issues, but the global norms of the international human rights approach makes the most sense in this case. When other kinds of rights claims are at issue

\footnotetext{
${ }^{52}$ Amnesty International, “Citizen Evidence Lab,” accessed June 15, 2016, https://citizenevidence.org/.

${ }^{53}$ Citizen Evidence Lab, “Toolbox,” accessed June 15, 2016, https://citizenevidence.org/toolbox/.

${ }^{54}$ Specially engineered technologies, such as Guardian Project's CameraV project and the International Bar Association's eyeWitness to Atrocities app (which is based on CameraV's technology) add additional metadata to a video or image as it is shot to enhance subsequent verifiability.

${ }^{55}$ Christoph Koettl, Citizen Media Research and Verification: An Analytical Framework for Human Rights Practitioners (Cambridge, UK: University of Cambridge Centre for Governance and Human Rights, 2016), 9.
} 
(especially claims to copyright/intellectual property or property ownership), the promotion of basic human rights, the prevention of war crimes and crimes against humanity, and respect for the dignity of survivors and victims should take precedence. Further, promotion of civil and political rights, and economic, social, and political rights should be given precedence whenever possible.

There is an equally powerful viewpoint in this context that states that the preservation and availability evidence of human rights violations and war crimes ought to be governed, if not determined, by the wishes of victims' families and survivors of such abuse-not norms generally associated with international non-governmental human rights organizations or archiving institutions generally centered in the global north. Survivors, victims' families, and local documentation groups may want to retain control of evidence so that they can use it in seeking justice, prevent the perpetrators or other enemies from gaining access to it and using it for purposes that go against their mandate, prevent it from ever being made public, delay access to it for some period of time, or even in rare circumstances, destroy it.

Archivist Michelle Caswell has made a practice-oriented version of this argument in numerous publications. She argues for a "survivor-centered approach" to archiving that recognizes that "past victims of human rights abuse depicted in these records did not choose to be documented." ${ }^{\prime 56}$ In order to restore and honor their agency as human beings with dignity and basic rights we ought to allow survivors to "maintain control over the decision-making processes related to records documenting their abuse, regardless of the nature of the institution - intergovernmental, governmental, or nongovernmental - that maintains custody over such records." ${ }^{57}$

Thus, rather than seeking to preserve as much evidence as possible, Caswell argues that the "primary ethical concern" of all involved in the human rights documentation process should be to honor the wishes and desires of those who survived violations and war crimes, and the relatives of those who were killed as a result..$^{58}$ In her view, this doesn't require turning all records over to community groups for archiving, but rather that those individuals most affected by war and human rights abuse should have a say in the archiving process through consultation, participation, and a seat at the decision-making table.

In traditional archiving situations, such questions and governance issues can be addressed through the process of negotiating donor agreements, setting restrictions on a collection, and determining conditions of use. In the context of preservation of video and images from social media and the Internet, however, such negotiations do not take place. Further, since many human rights preservation endeavors happen outside of academia and other archiving institutions, it will not always be possible to directly consult those affected by human rights abuse and war crimes.

One potential way of reconciling the survivor-centered approach with the realities of social media preservation would be to continue to monitor the status of the original instance of a publicly available video obtained from social media or the Internet in order to keep track of whether it goes private or is taken down by the host. If such a practice is put into place, the preserver would then have to decide whether it should flag this change in status as part of its preservation metadata, or even remove the material from its collection.

\section{Security Concerns}

Wherever one stands on the question of whether shared video and images should be archived without explicit consent and input of the creator, it is without question that when any kind of human rightsrelated content is preserved, the archiving individual or institution has an undeniable obligation to ensure that its actions are in the best interest of the affected individuals and communities, and also to protect the safety and security of the creator and all people who are depicted in the image or video. In the absence of explicit input from creators and those depicted, access to preserved material (especially videos and images that are taken down from social media platforms) should be

\footnotetext{
${ }^{56}$ Caswell, Toward a Survivor-Centered Approach, 309.

${ }^{57}$ Ibid., 308.

${ }^{58}$ Ibid., 309.
} 
limited to those individuals and institutions that are involved in the protection and promotion of human rights or have a direct interest in knowing exactly what happened as a survivor or relative of a victim. Other interests, such as historical clarification or academic research, will have to be handled on a case-by-case basis. There is unfortunately no easy way to determine the legitimacy of a particular request, or to identify exactly who has the authority to make such determinations. The ultimate goal of access policies must be to limit harm to vulnerable individuals and groups, and to promote a deeper understanding of a human rights abuse or conflict situation. At the end of the day, these are all judgment calls, and are debates in which survivors and relatives of victims should be central.

These issues are not unique to the human rights context-academic and institutional archives have been dealing with them for decades. Unfortunately, there are no simple answers. Each case involves accepting some degree of ambiguity and balancing of principles that may be in direct conflict with one another. ${ }^{59}$ Institutions and individuals engaged in preservation must decide what lengths they are willing to go to control access to sensitive material. Most importantly, are they prepared to go to jail to protect the content, and what resources should they devote to security, both in infrastructure or legal defense?

Thus, the institution or individual will need to determine in advance of engaging in preservation whether it has the resources, political capital, and institutional mandate to guard against demands for access to material by law enforcement, states, and other nefarious actors whose goal is national security, or protection of power or reputation, not the promotion of human rights in a country or region. At the end of the day, preservers will be faced with making judgments about what constitutes the public's interest and right to know. They will likely require strong legal counsel and very clear-cut data sharing policies to help them in this effort. ${ }^{60}$

\section{Access}

According to the Society of American Archivists' statement of values, "Archivists promote and provide the widest possible accessibility of materials, consistent with any mandatory access restrictions, such as public statute, donor contract, business/institutional privacy, or personal privacy. Although access may be limited in some instances, archivists seek to promote open access and use when possible." ${ }^{61}$ The hedges included in this statement highlight the reality that the ethics of providing access to archival materials is a "thorny problem." ${ }^{62}$ It is not a one and done policy decision, but instead requires constant deliberation and negotiation.

It would not make much sense to argue for open access to human rights media archives (even when all of the material collected may have public at one point), partly because this is not the goal of most human rights organizations (unlike, say an academic research archive) and partly because doing so would put many people at great risk. Preservers of human rights-related content must decide how much access to be granted for specific media, at what time, under what circumstances, and for what use.

Ideally the creator of the media, and those any victims or bystanders portrayed in it, should have the opportunity to determine how their creations and likenesses are used, but in the human rights context, this is not always practical, or even possible. In cases where this isn't possible, and where preserved material is nonpublic and particularly sensitive, one potential option is to convene a knowledgeable and empathetic board of trustees for a particular collection-made up of a mix of survivors, relatives of victims, affected community members, human rights advocates and investigators, lawyers, and other relevant specialists - to set policies and also act as a co-custodian or steward of a collection.

\footnotetext{
${ }^{59}$ The history of some of these debates can be found in Menzi L. Behrnd-Klodt and Peter J. Wosh, eds., Privacy and Confidentiality Perspectives: Archivists and Archival Records (Chicago: Society of American Archivists, 2005) and Danielson, The Ethical Archivist.

${ }^{60}$ Danielson, The Ethical Archivist.

${ }^{61}$ Society of American Archivists Core Values and Statement of Ethics, accessed June 17, 2016, http://www2.archivists.org/ statements/saa-core-values-statement-and-code-of-ethics.

${ }^{62}$ Elena S. Danielson, “The Ethics of Access," The American Archivist 52 (1989), 52-62.
} 
Michelle Caswell notes that consensus will not always be possible in such circumstances, so policies should accommodate multiple viewpoints whenever possible. This board can either set criteria for access (i.e., what should be public, if anything, and what should be restricted), review specific requests for restricted material when they arise, or set general guidelines for the use of material in the collection and the way that it is credited. It can also establish a date or circumstance at which a closed image or video collection might become open or at least less restricted. The board can also determine whether investigators from criminal tribunals, truth commissions, or other official investigative bodies should be give unrestricted access to preserved materials. Trustees and advisors must be mindful that the perpetrator in and inquiry will have a legitimate case or access to the material as well-potentially exposing creators or those portrayed in media to various levels of intimidation or actual physical harm.

Integrating such advisory groups present numerous challenges in the archiving context, but Caswell provides several examples of successful community partnerships including the University of Texas Human Rights Documentation Initiative's South Asian American Digital Archive (SAADA). SAADA involves partnerships with two grassroots activist networks documenting forced deportation of immigrants from the Indian subcontinent after September 11 and several initiatives currently taking place on Indigenous archives in Australia. ${ }^{63}$

\section{Privacy and Safety}

Whenever access is granted to a human rights media collection, the preserving institution or individual has a strong obligation to protect the privacy of the sources of the audiovisual media, their creators, and the individuals who appear in them. It will likely be impossible to fully anonymize any of these actors, and indeed, the interests of justice and accountability might not be served by doing so, but every effort must be undertaken to ensure their safety. This might require redacting certain metadata before a collection is accessed, or using a blurring tool (such as that offered by YouTube or other video/image processing software) to hide the faces of individuals before a particular video or image is made public or released to the custody of another institution, researcher, or human rights advocate. It will also certainly require the signing of a nondisclosure agreement, although such documents are unlikely to provide full privacy protection.

Again, such issues are nothing new - the requirement to balance personal privacy and the public interest has been the subject of debate for decades. ${ }^{64}$ The stakes are dramatically heightened in the human rights context, where much more than personal reputation or propriety (or national pride) is at stake. There are numerous examples of this kind of situation in the archiving world (e.g., the Boston College Troubles Archive or the South African Truth and Reconciliation Commission Archive), and each case seems to be handled as a unique challenge. In some cases, the desire to protect basic human rights will require restricting access to a collection, and in others in might require making collections available that will almost certainly generate risks to personal privacy and security. In some cases, compromises will need to be worked out in which metadata for a particular piece of media is available, but not the image or video in question. This will of course prevent full use of the material, but it will at least alert investigators that such content exists.

A guiding principle ought to be that any disclosure of private data or individual or community identity must be directly related to the protection and promotion of basic human rights or historical clarification. It must either provide evidence that a violation has taken place or information about perpetrators. Such information should not be released upon request without scrutiny or into the hands of individuals or institutions that do not have human rights and truth telling as core objectives. Actors who are suspected of wanting to use media collections to target activists or community members should be denied access whenever legally possible. Disclosure of information should not harm the ability of an individual to lead a decent life unless that person has committed war crimes or crimes against humanity, or has information that is directly linked to such event. Further, the use of face-blurring and other privacy enhancing techniques should be used whenever possible.

\footnotetext{
${ }^{63}$ Caswell, Toward a Survivor-Centered Approach.

${ }^{64}$ Behrnd-Klodt and Wosh, Privacy and Confidentiality Perspectives.
} 
This is an evaluation of the privacy/access conundrum that is not binary, but rather is contextual. ${ }^{65}$ Decisions about whether to grant access to a collection or piece of media is based upon an evaluation of the use to which it will be put, the context in which it will be used, who will be using it, what the potential harms are to the individuals portrayed in the media, to communities, and societies, and what they potential benefits are to those same entities. ${ }^{66}$ Whenever possible, these decisions should be made with affected individuals and community representatives at the table.

One potential solution to the challenge of privacy, security, and consent that gives primacy to the desires of creators, can be seen in a recent project involving the collection of tweets surrounding the Black Lives Matter Movement by Deen Freelon, Charlton D. Mcllwain, and Meridith D. Clark. It must be noted, however, that the policies they developed to manage a large collection of tweets purchased from Twitter for research purposes (and therefore in compliance with the companies' terms of service) might hinder the preservation of the most relevant images and videos in the human rights context. Specifically, in their public-facing report, they provide only a link to a tweet rather than quoting it in print, which gives the user the opportunity to delete the material if he or she does not want it to be disseminated in such a way. Further, they limit their discussion of specific tweets to those that were posted by users who had 3,000 followers or more, or where verified by the company, and had a minimum of 100 retweets by the time that they conducted their analysis. They noted that this would minimize the potential for shining an "unwanted spotlight on previously obscure content" or "exposing relatively unknown users to unwanted public scrutiny." ${ }^{67}$

While the authors of this study recognize that they could have made some Twitter users unhappy by including their names or tweets in the report, they feel that their "ethical choices strike a balance between the individual rights of the parties to this conversation and the right of the public to know how a movement of such political significance rose to prominence online." 68 They also made it clear that anyone who felt they were harmed by the report should contact the authors to discuss ways of mitigating the harm of their inclusion, and that when they made the database of tweets available to the public after an embargo period, they would release only tweet IDs to limit access to material that had been deleted or otherwise protected. ${ }^{69}$ While the authors presumably retain the original content in their collection, outside users would not have access to at least some content that could be useful in an investigation or inquiry. This would of course protect creators from unwanted publicity, but it limits the value of the collection as a whole.

\section{Conclusion: Tension Remains}

A core tension remains after this analysis of the preservation of human rights-related video: whose needs are being met by its preservation and who ought to control the storage and use of this content? One perspective focuses on the need to preserve evidence of violations for justice and accountability efforts (both at the national and international levels), advocacy, and historical clarification. This position is most often voiced by international human rights organizations and institutions and their affiliates. Another viewpoint focuses on the ethical duty to protect individuals and respect their wishes even when higher-level justice and accountability efforts may suffer. People and organizations closer to actual production of evidence-whether they are activists or organizations that support them directly-most frequently express this view to me. Obviously most human rights practitioners recognize the value of both, but opinions differ on which one ought to be prioritized.

\footnotetext{
${ }^{65}$ Steven Bingo uses this term in a similar way. See: Steven Bingo, "Of Provenance and Privacy: Using Contextual Integrity to Define Third-Party Privacy," The American Archivist 74 (2011), 506-521.

${ }^{66}$ See Sonia Yaco, "Balancing Privacy and Access in School Desegregation Collections: A Case Study," The American Archivist 73, no. 2 (2010), 637-668 for an excellent discussion of this issue in the context of U.S. school desegregation records. She highlights the legal distinction between disclosing private information and making it public. This could be a useful fulcrum for publishing some metadata regarding a particular video or image while not releasing the content itself.

${ }^{67}$ Deen Freelon, et al., Beyond the Hashtags: \#Ferguson, \#Blacklivesmatter, and the Online Struggle for Offline Justice (Washington, DC: Center for Media and Social Impact, 2016), 86.

${ }^{68}$ Freelon, et al., Beyond the Hashtags, 86.

${ }^{69}$ Ibid., 87.
} 
Perhaps one possible source of guidance on this issue is the recent European Court of Justice's decision on the right to be forgotten, in which it recognized that citizens could petition to have online links removed from search engine results that contained inaccurate, inadequate, irrelevant, or excessive information, but that such requests would be subject to balancing tests against other fundamental rights. Specifically, decision makers would have to evaluate "the type of information in question, its sensitivity for the individual's private life, and the interest of the public in having access to that information." ${ }^{70}$ The court ultimately made it clear that the individual's right to be forgotten must always be balanced with the public's right to know. While the ruling does not present a clear-cut answer for every case, it does provide a normative framework for determining whether or not content should be preserved and/or made accessible in the absence of explicit permission by the creator and those individuals portrayed in it.

A second source of guidance is the growing movement to erase the silences that exist in current archives, accountability efforts, and academic scholarship. These efforts rest upon the twin pillars of widening the scope of collection efforts, and giving the people whose lives are being documented a say in how these collections are created, stored and used. An excellent example in this context is the "Documenting the Now" project, which seeks to archive Twitter, social media, and Internet resources relating to activism surrounding race, police brutality and similar topics in the United States. The team leading this project acknowledges that our understandings of the past are "deeply tied to the traces that are created and remain in our archives," and that what is absent from archives speaks just as loudly as what is present. ${ }^{71}$ Thus, preservation efforts have an obligation toensurethatnogroupsarebeingintentionally orinadvertently silenced, and that thepeople and communities whose voices and creations are being archived must retain at least some control over what is collected, how it is collected, and how these collections are governed in the future.

\section{Acknowledgements}

This work was supported by grants from the MacArthur Foundation, Oak Foundation, and Humanity United. The author would like to thank Yvonne $\mathrm{Ng}$ for her critical comments and collegiality throughout the drafting of this article. He would also like to thank Wendy Betts and Jarrett Drake for their feedback on later versions.

\section{Bibliography}

Aronson, Jay D., Shicheng Xu, and Alex Hauptmann. Video Analytics for Conflict Monitoring and Human Rights Documentation. Pittsburgh, PA: Carnegie Mellon University Center for Human Rights Science, 2015.

Baylis, Elena. "Tribunal-Hopping With the Post-Conflict Justice Junkies." Oregon Review of International Law 10 (2008): 361-390.

Behrnd-Klodt, Menzi L. and Peter J. Wosh, eds. Privacy and Confidentiality Perspectives: Archivists and Archival Records. Chicago: Society of American Archivists, 2005.

Bickford, Louis. "The Archival Imperative: Human Rights and Historical Memory in Latin America's Southern Cone." Human Rights Quarterly 21, no. 4 (1999): 1097-1122. https://doi.org/10.1353/hrq.1999.0048

Bingo, Steven. "Of Provenance and Privacy: Using Contextual Integrity to Define ThirdParty Privacy." American Archivist 74 (2011): 506-521. https://doi.org/10.17723/ aarc.74.2.55132839256116n4

Caswell, Michelle. "Defining Human Rights Archives: Introduction to the Special Double Issue on Archives and Human Rights." Archival Science 14, no. 3-4 (2014): 207-213. https://doi.org/10.1007/s10502-014-9226-0

\footnotetext{
${ }^{70}$ European Commission, "Factsheet on the "Right to be Forgotten" Ruling (C-131/12)," accessed September 19, 2016, http://ec.europa.eu/justice/data-protection/files/factsheets/factsheet data protection en.pdf. See also paragraph 81 of the original ruling, Google Spain SL, Google Inc. v Agencia Española de Protección de Datos (AEPD), accessed September 19, 2016, http://curia.europa.eu/juris/documents.jsf?num=C-131/12.

${ }^{71}$ Maryland Institute for Technology in the Humanities, "Introducing Documenting the Now," accessed June 17, 2016, http://mith.umd.edu/introducing-documenting-the-now/.
} 
-------. "Toward a Survivor-Centered Approach to Records Documenting Human Rights Abuse: Lessons From Community Archives." Archival Science 14, no. 3-4 (2014): 307-322. https://doi.org/10.1007/s10502-014-9220-6

Crunelle, David. "The Art of Being in the Wrong Place At the Right Time: Behind the Scenes of Social Media Newsgathering." (2016). Accessed September 19, 2016. https://medium. com/@emhub/the-art-of-being-in-the-wrong-place-at-the-right-time-behind-the-scenesof-social-media-3ee558630e93\#.7ls6u8wln.

European Commission. "Factsheet on the "Right to be Forgotten" Ruling (C-131/12)." Accessed September 19, 2016. http://ec.europa.eu/justice/data-protection/files/factsheets/factsheet data protection en.pdf.

Danielson, Elena S. "The Ethics of Access." The American Archivist 52 (1989): 52-62. https://doi. org/10.17723/aarc.52.1.6m2m41171612j058

-------. The Ethical Archivist. Chicago: Society of American Archivists, 2010.

Freelon, Deen, Charlton D. Mcllwain, and Meredith D. Clark. Beyond the Hashtags: \#Ferguson, \#Blacklivesmatter, and the Online Struggle for Offline Justice. Washington, DC: Center for Media and Social Impact, 2016.

Google Spain SL, Google Inc. v Agencia Española de Protección de Datos (AEPD). Accessed September 19, 2016. http://curia.europa.eu/juris/documents.jsf?num=C-131/12.

Greene, Mark A. "The Power of Meaning: The Archival Mission in the Postmodern Age." The American Archivist 65 (2002): 42-55. https://doi.org/10.17723/aarc.65.1.1914668v881wv19n

and Dennis Meissner. "More Product, Less Process: Revamping Traditional Archival Processing." The American Archivist 68 (2005): 208-263. https://doi.org/10.17723/ aarc.68.2.c741823776k65863

Gregory, Sam. “Do We Need a Dedicated Repository for Human Rights Media?" (January 2015). Accessed June 17, 2016. http://blog.witness.org/2015/01/one-human-rights-archive/.

Harris, Verne. "Claiming Less, Delivering More: A Critique of Positivist Formulations on Archives in South Africa." Archivaria 44 (1997): 132-140.

-------. Archives and Justice: A South African Perspective. Chicago: Society of American Archivists, 2007.

Hobbs, Catherine. "The Character of Personal Archives: Reflections on the Value of Records of Individuals." Archivaria 52 (2001): 126-135.

International Council on Archives Human Rights Working Group. "Basic Principles on the Role of Archivists in Support of Human Rights (Draft)." June 21, 2014. Accessed June 9, 2016. http://www.icarchives.webbler.co.uk/15999/news-and-events/basic-principles-on-therole-of-archivists-in-support-of-human-rights-give-your-opinion.html.

International Criminal Court. "eCourt Protocol." Accessed June 15, 2016. https://www.icc-cpi.int/ iccdocs/doc/doc1695618.pdf.

Jimerson, Randall C. Archives Power: Memory, Accountability, and Social Justice. Chicago: Society of American Archivists, 2009.

Joinet, Louis. "The Administration of Justice and the Human Rights of Detainees Question of the Impunity of Perpetrators of Human Rights Violations (Civil and Political)," E/CN.4/ Sub.2/1997/20 (26 June 1997).

Koettl, Christoph. Citizen Media Research and Verification: An Analytical Framework for Human Rights Practitioners. University of Cambridge Centre of Governance and Human Rights, 2016.

Piracés, Enrique. “Trusted Timestamping." Accessed September 19, 2016. https://www.rightslab. org/vault/faq.php\#Trusted Timestamping.

. "VideoVault." Accessed April 24, 2017. https://www.bravenewtech.org.

Quintana, Antonio González. Archival Policies in the Protection of Human Rights. Paris: International Council on Archives, 2009.

Responsible Data Forum. "Managing Data: Setting Up the Data Infrastructure." Accessed June 15, 2016. https://responsibledata.io/resources/handbook/chapters/chapter-02-managing-data. html\#a-home-for-healthy-data.

Rieff, David. In Praise of Forgetting: Historical Memory and Its Ironies. New Haven: Yale University Press, 2016. 
Schwartz, Joan M. and Terry Cook. "Archives, Records, and Power: The Making of Modern Memory." Archival Science 2 (2002): 1-19. https://doi.org/10.1007/BF02435628

Silverman, Craig. Lies, Damn Lies, and Viral Content: How News Websites Spread (and Debunk) Online Rumors, Unverified Claims, and Misinformation. New York: Tow Center for Digital Journalism/Columbia Journalism School, 2015.

-------, ed. The Verification Handbook. Maastricht, the Netherlands: European Journalism Center, 2013.

Stevenson, Karen. "Curating Eyewitness Videos for Data on Transphobic Violence." (June 2016). Accessed September 19, 2016. https://lab.witness.org/curating-eyewitness-videos-datatransphobic-violence/.

Stinnett, Graham. Rebel Collectors: Human Rights and Archives in Central America and the Human Rights Commission of El Salvador and the Resource Center of the Americas, 1978-2007. Winnipeg, Manitoba: University of Manitoba andUniversity of Winnipeg, 2010.

Trouillot, Michel-Rolph. Silencing the Past: Power and the Production of History. Boston: Beacon Press, 1997.

Tucker, Susan. "Tacitly the Work of Women: Personal Archives and the Public Memory of Families." In Perspectives on Women's Archives, edited by Tanya Zanish-Belcher and Anke Voss, 147176. Chicago: Society of American Archivists, 2013.

Weld, Kirsten. Paper Cadavers: The Archives of Dictatorship in Guatemala. Durham: Duke University Press, 2014. https://doi.org/10.1215/9780822376583

WITNESS. "Activists' Guide to Archiving Video." (n.d.). Accessed June 15, 2016. https:// archiveguide.witness.org/.

-------. "Ethical Guidelines: Using Eyewitness Videos in Human Rights Reporting \& Advocacy." (n.d.). Accessed June 13, 2016. https://library.witness.org/product/video-as-evidenceethical-guidelines/.

Yaco, Sonia. "Balancing Privacy and Access in School Desegregation Collections: A Case Study." The American Archivist 73 (2010): 637-668. https://doi.org/10.17723/aarc.73.2.h1346156546161m8 